\title{
Characterization of Expressed Genes Under Ozone Stress in Soybean
}

\author{
Jun-Cheol Moon ${ }^{1}$, Sung Don Lim, Won Cheol Yim², Kitae Song ${ }^{2}$, Byung-Moo Lee ${ }^{2}$ * \\ ${ }^{1}$ Agriculture and Life Sciences Research Institute, Kangwon National University, Chuncheon 200-713, Republic of Korea \\ ${ }^{2}$ Department of Life Science, Dongguk University-Seoul, Seoul 100-715, Republic of Korea
}

\begin{abstract}
To identify the genes specifically or predominantly expressed in ozone-fumigated leaves of two soybean cultivars: Jinpumkong and Cheongjakong, expression levels of mRNA were investigated using differential banding patterns on agarose gel. A total of 408 bands differently expressed after ozone fumigation was identified; 153 of which were up-regulated while 225 were down-regulated. Using BLASTx, the putative functions of the expressed sequence tags were determined. The 178 ozone-regulated differentially expressed genes (DEGs) matched with the previously known genes with high significance. The putative functional classes of these DEGs were categorized by two databases: Gene Ontology and MIPS. Based on the Gene Ontology database, majority of the DEGS have molecular function related to transferase activity. Most of them are involved in the cellular and metabolic processes. Cytoplasmic part and cell part were the primary types of cellular component in the ozone-responding DEGs. Whereas findings using the MIPS database revealed the function distribution of up-regulated DEGs across all classes. Most of the ozone-regulated genes identified in this study are related to biotic and abiotic stresses. The characterized ESTs will serve as useful data to provide a better understanding of the molecular basis and transcript profiles.
\end{abstract}

Keywords Differentially expressed gene, Ozone, Soybean, Transcripts

\section{INTRODUCTION}

One of the best characterized types of oxidative stress is exposure to high concentrations of ozone. Anthropogenic hydrocarbons and oxides of nitrogen $\left(\mathrm{NO}, \mathrm{NO}_{2}\right)$ and sulfur (SOx) react with solar UV radiation to generate ozone $\left(\mathrm{O}_{3}\right)$. Stratospheric ozone is beneficial because it shields the earth from UV irradiation; however, tropospheric ozone is harmful to life because it is a highly reactive oxidant. The negative effects of ozone on plants include decreasing photosynthesis rates, leaf injury, reducing growth of shoots and roots, accelerating senescence, and reducing crop yield. ROS damaging free radicals and their products react with proteins, DNA, and membrane lipids to reduce photosynthesis, increase electrolyte leakage, and accelerate senescence and cell death (Rao et al. 2000; Sharma and Davis 1997). Elevated levels of ROS induce the biosynthesis of antioxidant molecules, including ascorbates, polyamines, and glutathione (Blokhina et al. 2003; Conklin and Last 1995; Creissen et al. 1999). Oxidative stress increases the activity of antioxidant enzymes, such as superoxide dismutase (SOD), peroxidase, catalase, and glutathione S-transferase (Blokhina et al. 2003; Ludwikow et al. 2004; McClung 1997; Mittler 2002; Tognolli et al. 2002). The transcription and activity of several ROS change drastically in response to ozone stress. In addition to antioxidant genes, a number of other genes are regulated by ozone stress at the transcript and protein levels in Arabidopsis and rice (Agrawal et al. 2002; Ludwikow et al. 2004).

The effects of ozone resemble characteristics of systemic acquired resistance (SAR) (Greenberg et al. 1994) and hypersensitive resistance (HR) (Pasqualini et al. 2003; Tenhaken et al. 1995). In addition, its effects are similar to responses to ethylene, salicylic acid, and jasmonic acid

Received July 16, 2013; Revised August 14, 2013; Accepted August 17, 2013; Published September 30, 2013

*Corresponding author Byung-Moo Lee, bmlee@dongguk.edu, Tel: +82-2-2260-3307, Fax: +82-2-2269-2770 
(Overmyer et al. 2003; Rao et al. 2002; Tamaoki et al. 2003a).

Soybeans are a major food crop worldwide, and can supply edible vegetable oil and high quality protein. The other domains and derivatives of the seed have substantial economic importance for a wide range of industrial, food, pharmaceutical, and agricultural products. In many studies, soybeans have been the target of various stress effects. Using meta-analytic techniques, Morgan et al. (2003) quantitatively summarized the responses of soybeans to chronic ozone exposure of $70 \mathrm{ppb}$. At maturity, the average shoot biomass was reduced to $34 \%$, while the yield decreased to $24 \%$. In previous studies, chronic ozone exposure has caused serious biomass and seed production losses even at low concentrations, and often in the absence of visible symptoms Fiscus et al. (1997). Furthermore, Renaud et al. (1997) reported that ozone stress can decrease root biomass in alfalfa.

To understand the molecular basis of the stress response, the differentially expressed genes (DEGs) in stress-induced leaves must be identified. DEGs are only expressed at low levels and their transcripts are difficult to detect in the abundant mRNA within tissues. To detect DEGs transcribed at low levels, highly specific polymerase chain reaction (PCR) amplification is required. Novel annealing control primer (ACP)-based DDRT-PCR technology has been used to identify differentially expressed genes in tissues Hwang et al. (2004). This method specifically targets sequence hybridization to the template via a polydeoxyinosine linker Hwang et al. (2003).
The objective of this study was to isolate and characterize the differentially expressed genes of soybean leaves treated with ozone. ACP-based DDRT-PCR was used to identify the up-regulated and down-regulated DEGs in the tissue. And the putative functions of the DEGs were categorized using Gene ontology and the Munich Information Center for Protein Sequences (MIPS) databases.

\section{MATERIALS AND METHODS}

\section{Plant materials and ozone treatment}

In order to select plants that could be used for ozone stress test, this study used the previous data on physiological characteristics (Lee et al. 2006) and selected two cultivars of soybean [Glycine $\max$ (L.) Merr]: Jinpumkong and Cheongjakong. The plants were grown in a greenhouse at the National Institute of Crop Science (NICS) in Korea, and the ozone stress was treated at the V5 stage. Ozone-sensitive (cv. Jinpumkong) and ozone-insensitive (cv. Cheongjakong) soybeans were fumigated with $200 \mathrm{ppb}$ of ozone for $4 \mathrm{~h}$ in 5 consecutive days in an airtight greenhouse (Fig. 1).

\section{Total RNA extraction and annealing control primer (ACP)-based differential display}

The total RNA was isolated from $200 \mathrm{mg}$ of soybean leaves using TRIZOL reagent (Invitrogen), as instructed by the manufacturer, which was then employed in the synthesis of first-strand cDNA by reverse transcriptase, as described

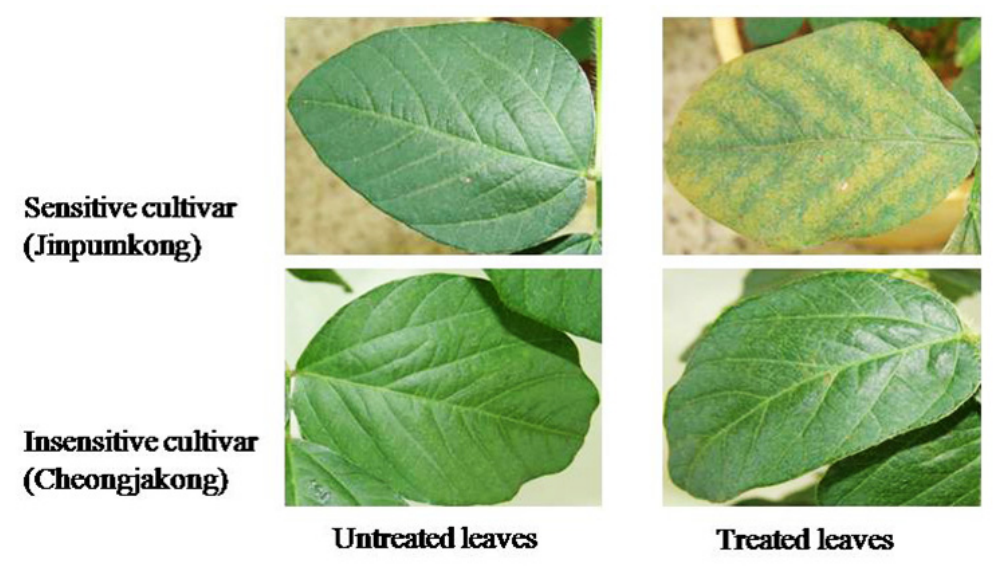

Fig. 1. The soybean leaves treated with $200 \mathrm{ppb}$ of ozone for $4 \mathrm{~h}$ in 5 consecutive days. 
in Hwang et al. (2003). First-strand cDNA synthesis was performed using the dT-ACP1 primer (GeneFishing ${ }^{\text {TM }}$ DEG kits, Seegene, Korea); and $3 \mu \mathrm{g}$ of total RNA was incubated with $2 \mu$ of dT-ACP1 $(10 \mu \mathrm{M})$ at $80^{\circ} \mathrm{C}$ for $3 \mathrm{~min}$. Subsequently, reverse transcription was performed with a total volume of $20 \mu \mathrm{l}$ containing purified total RNA, $4 \mu \mathrm{l}$ of $5 \mathrm{x}$ first strand buffer (Invitrogen), $5 \mu \mathrm{l}$ dNTPs (each 2 $\mathrm{mM}), 0.5 \mu \mathrm{l}$ of RNasin Plus RNase Inhibitor (40 U/ $\mu 1$, Promega), and $1 \mu \mathrm{l}$ of SuperScript ${ }^{\mathrm{TM}}$ II RNase H-Reverse Transcriptase (200 U/ $\mu 1$, Invitrogen) for $1.5 \mathrm{~h}$ at $42^{\circ} \mathrm{C}$. The first-strand cDNA samples were diluted with $80 \mu \mathrm{l}$ of DNase-free water and were used as template for secondstrand cDNA synthesis by random PCR amplification using dT-ACP2 and one of 120 arbitrary ACPs (GeneFishing ${ }^{\text {TM }}$ DEG kits, Seegene, Korea) as primers. The second-strand cDNA synthesis was performed in a final reaction volume of $20 \mu \mathrm{l}$ containing diluted first-strand cDNA (50 ng), $2 \mu \mathrm{l}$ of $5 \mu \mathrm{M}$ arbitrary ACP primer, $1 \mu 1$ of $10 \mu \mathrm{M}$ dT-ACP2, and $10 \mu \mathrm{l}$ of $2 \mathrm{x}$ SeeAmp ${ }^{\mathrm{TM}} \mathrm{ACP}^{\mathrm{TM}}$ Master Mix (GeneFishing ${ }^{\mathrm{TM}}$ DEG kits, Seegene, Korea). The PCR protocol for second-strand synthesis is consisted of one cycle at 9 $4^{\circ} \mathrm{C}$ for $1 \mathrm{~min}$, followed by $50^{\circ} \mathrm{C}$ for $3 \mathrm{~min}$, and $72^{\circ} \mathrm{C}$ for 1 min. A total of 40 cycles of amplification which include denaturation at $95^{\circ} \mathrm{C}$ for $20 \mathrm{sec}$, annealing at $65^{\circ} \mathrm{C}$ for 40 sec, extension at $72^{\circ} \mathrm{C}$ for $40 \mathrm{sec}$, and a final extension step of $5 \mathrm{~min}$ at $72^{\circ} \mathrm{C}$ was used. The amplified products were separated on $2 \%$ agarose gels, and then stained with ethidium bromide.

The differentially expressed transcripts were eluted and cloned into a T\&A cloning vector (Real Biotech Corp., Taiwan). To confirm the identities of the insert DNAs, isolated plasmids were sequenced (Bionics, Korea).

\section{Annotation of soybean EST genes and function}

The EST sequences were decoded to FASTA format by the PHRED program, using default parameters Ewing and Green (1998). These sequences were filtered to remove contaminants such as vector and bed quality sequences, using the LUCY2 tool Li and Chou (2004). The CAP3 program was used to cluster the ESTs so that they directly assemble to contig and siglet Huang and Madan (1999). The sequence homologies were determined by BLASTx of the NCBI nr database (http://www.ncbi.nlm.nih.gov), using the default options. Non-significant results were removed using a cut-off e-value of $10^{-4}$. Functions were assigned using the Gene Ontology database (http://www. geneonotology. org) and the Munich Information Center for Protein Sequence (MIPS) database (http://mips.gsf.de/ proj/funcatDB). All the EST data are publicly available through the NCBI, with GenBank dbEST accession nos. EG702072 - EG702322.

\section{RESULTS AND DISCUSSION}

To identify the genes specifically or predominantly expressed in ozone-treated soybean leaves, differential expression levels of the mRNA fragments of treated and untreated leaves were investigated using differential banding patterns in agarose gels. The differentially expressed gene (DEG) bands were detected in the ozone-treated and -untreated leaves using a combination of 120 arbitrary primers and two anchored oligo (dT) primers from GeneFishing ${ }^{\mathrm{TM}}$ DEG kits (Seegene, Korea). A total of 408 DEGs

Table 1. Patterns of up- and down-regulated differentially expressed genes in ozone treated soybean.

\begin{tabular}{ccc}
\hline Regulated & $\begin{array}{c}\text { Cultivar } \\
\text { (sensitive) }\end{array}$ & $\begin{array}{c}\text { Cheongjakong } \\
\text { (insensitive) }\end{array}$ \\
\hline Up & 61 & 92 \\
Down & 225 & 30 \\
\hline
\end{tabular}

Table 2. Summary of ESTs from soybean leaves treated with ozone.

\begin{tabular}{lcc}
\hline \hline & Number & $\begin{array}{c}\text { Percentage } \\
(\%)\end{array}$ \\
\hline Total clones & 408 & \\
Sequenced clones & 382 & 93.6 \\
Non-sequenced clones & 26 & 6.4 \\
Non-redundant sequence & 223 & 54.7 \\
Cluster & 20 & \\
$\quad$ Redundancy & 179 & 43.9 \\
Singlet & 203 & \\
Blast match & 178 & 79.8 \\
Blast no-match & 45 & 20.2 \\
\hline
\end{tabular}


were expressed in the ozone-treated soybean leaves (cv. Cheongjakong and Jinpumkong); of which 153 DEGs were up-regulated while 225 were down-regulated (Table 1).

The nucleotide sequences of 382 DEGs in the ozonefumigated treatments were analyzed; and their putative identification was conducted using BLASTx. Result of homology searches revealed that 178 (79.8\%) of the identified DEGs after ozone treatment matched well with the previously known genes. The sequenced clones of the ESTs from the ozone-treated soybean leaves included 223 unique clones $(54.7 \%)$, which in turn consisted of 20 assembled sequences and 203 singletons. The sequences of 179 clones were assembled into 20 clusters with a redundancy of $43.9 \%$ (Table 2).

The observed DEGs, such as those encoding glutathione $S$-transferase, copper-binding protein, ascorbate peroxidase, ribulose-1,5-bisphosphate carboxylase/oxygenase activase, lipoxygenase, $\mathrm{Cu} / \mathrm{Zn}$ superoxide dismutase, chlorophyll $\mathrm{a} / \mathrm{b}$-binding protein, and photosynthesis and antioxidant enzymes, were previously reported as ozone responsive (Conklin and Last 1995; Glick et al. 1995; Kliebenstein et al. 1998; Kubo et al. 1995; Maccarrone et al. 1992; Miller et al. 1999; Tamaoki et al. 2003b; Tamaoki et al. 2003a).

Glutathione $S$-transferase was up-regulated in response to ozone treatment. Kawasaki et al. (2001) reported the up-regulation of many genes encoding glycine-rich proteins, ABA and stress-induced proteins, metallothionein-like proteins, glutathione S-transferase, and ascorbate peroxidase in salt-tolerant rice.

Seki et al. (2002) identified cold-, drought-, and salinityinduced target genes as well as stress-related transcription factor family members such as helix-loop-helix using Arabidopsis cDNAs. These results suggest cross-talk between the salt and drought stress signaling processes. Helix-loop-helix was down-regulated in response to ozone treatment, inferring cross-talk between ozone stress and other stress signaling processes.

For the identified DEGs, 11 up-regulated and 2 downregulated DEGs overlapped in the sensitive and insensitive cultivars of the ozone-treated leaves (Fig. 2). These overlapping genes were subsequently categorized with a binding molecular function based on the Gene Ontology database.

Plastidic aldolase, MSS4 (Saccharomyces cerevisiae protein), and metalloendorproteinase were shown to overlap in the up-regulated DEGs by ozone response. The ribulose1,5-bisphosphate carboxylase small subunit and chlorophyll $\mathrm{a} / \mathrm{b}$ binding protein overlapped in the down-regulated DEGs by ozone response (Fig. 3).

Plastidic aldolase (AldP) overlapped in the up-regulated DEGs by ozone response. AldP is involved in the photosynthetic carbon reduction cycle and catalyzes the cleavage of fructose-1,6-bisphosphate (FBP) into D-glyceraldehyde3-phosphate (GAP) and dihydroxyacetone phosphate (DHAP). Two forms of aldolase are present in higher plants: cytoplasmic and plastidic. The cytoplasmic aldolase (AldC) gene is inducible under anaerobic conditions and is considered to have an important role in producing ATP by stimulating glycolysis under such conditions (Andrews et al. 1994; Umeda and Uchimiya 1994). Its expression is regulated by light Kagaya et al. (1995). The isolation of two AldP genes from a salt-tolerant Nicotiana species, $N$. paniculata, and their expression regulation among three Nicotiana species were compared, showing varied tolerant reaction to salt stress Yamada et al. (2000).

Putative functions of the identified DEGs were determined using the Gene Ontology database. Majority of the ozone-
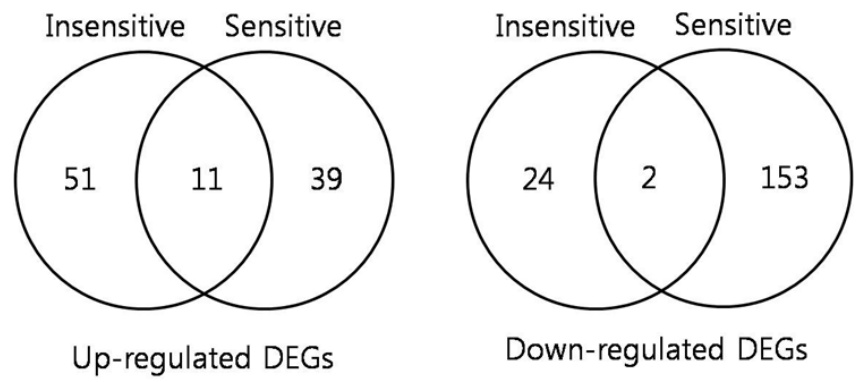

Fig. 2. Distribution of the DEGs according to type of ozone response. 
responsive DEGs identified have molecular function related to transferase activity, while the down-regulated DEGs in insensitive cultivar fell under the class possessing structural molecule activity. Most of them are involved in the cellular and metabolic processes. However, stimulus response and the developmental process were the major classes of the up-regulated DEGs in the ozone-insensitive cultivar. Furthermore, cytoplasmic and cell parts were the primary cellular component types involved in response to ozone.

The functional classes of the up-regulated DEGs in the ozone sensitive and insensitive cultivars were distributed across all classes within the MIPS database (Fig. 3). Biogeneisis of cellular components $(31.7 \%)$ and protein with binding function of cofactor requirement $(27.9 \%)$ were the major classes in the up-regulated DEGs. The other functions identified include protein fate (23.4\%), metabolism (22.3\%), cellular communication/signal transduction mechanism (21.4\%), unclassified proteins $(21.1 \%)$, regulation of metabolism and protein function $(20.9 \%)$, transport facilities and transport routes (20.9\%), subcellular localization (19.8\%), energy (17.3\%), cellular transport, cell rescue, defense and virulence (14.6\%), cell cycle and DNA processing (12.1\%), transcription (11.6\%), interaction with the environment $(11.4 \%)$, cell fate $(10.7 \%)$, protein synthesis $(7.7 \%)$, and transposable elements, viral and plasmid proteins $(4.0 \%)$. Fourteen classes overlapped in the up-regulated DEGs, while two classes overlapped in the down-regulated DEGs.

Approximately half of the ozone-responsive downregulated DEGs were unclassified proteins (52.2\%). The down-regulated DEGs responding to ozone application were categorized according to protein fate (19.4\%), meta-
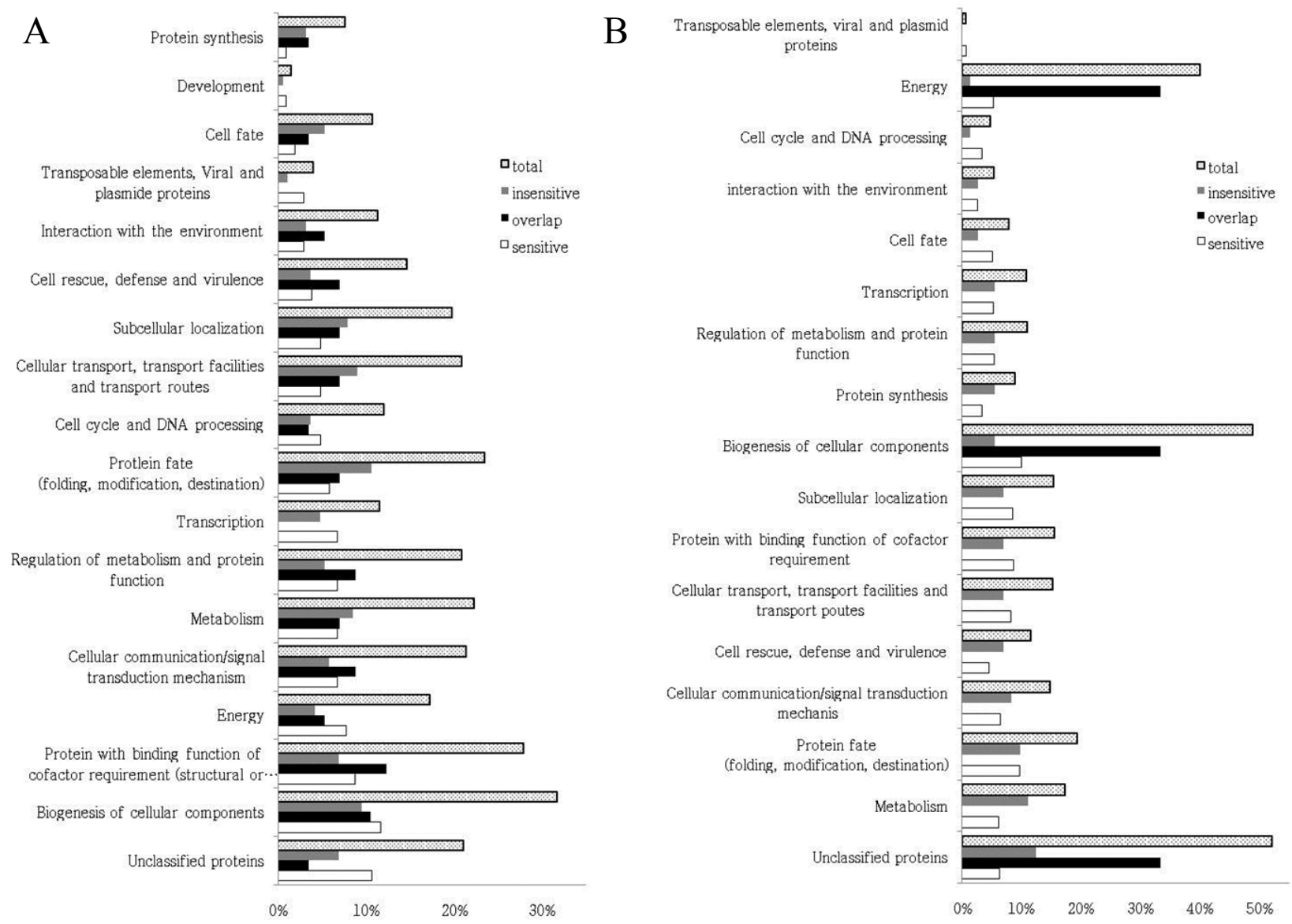

Fig. 3. Functional distribution of the ozone-regulated DEGs. The putative functional categories of the DEGs were determined using the MIPS database. A: Up-regulated, B: Down-regulated. 
bolism (17.3\%), protein with binding function of cofactor requirement (15.6\%), subcellular localization (15.4\%), cellular transport, transport facilities and transport routes (15.2\%), cellular communication/signal transduction mechanism (14.9\%), cell rescue, defense and virulence (11.5\%), regulation of metabolism and protein function (11.0\%), transcription $(10.8 \%)$, protein synthesis $(8.9 \%)$, cell fate (7.9\%), interaction with the environment (5.4\%), cell cycle and DNA processing $(4.7 \%)$, and transposable elements, viral and plasmid proteins $(0.7 \%)$.

In a previous study using pepper, the common types of functions for up- and down-regulated ozone stress-regulated genes were related to metabolism and defense Lee and Yun (2006). The ESTs of $\mathrm{O}_{3}$-exposed Arabidopsis were categorized as cell rescue/defense genes for the up-regulated genes, and for energy category in the down-regulated genes Tamaoki et al. (2003a).

\section{CONCLUSION}

This study was conducted to identify and characterize the genes that predominantly responded to ozone stress in soybean. Of the 408 differentially expressed bands, 153 were up-regulated while 225 were down-regulated. Results further demonstrated various functions of the DEGs, majority of which were implicated to have molecular function related to transferase activity, and are involved in cellular and metabolic processes. DEG profiling by ozone treatment highlights the possible signaling pathways and molecular biological process for future research. More so, this study serves as a benchmark in finding out the regulatory pathways involve in acclimation responses to ozone, as well as relationships among the DEGs responsive to ozone and other abiotic stress.

\section{ACKNOWLEDGMENT}

This work was carried out with the support of "Cooperative Research Program for Agriculture Science \& Technology Development (Project No. PJ907047)", Rural Development Administration, Republic of Korea.

\section{REFERENCES}

Agrawal GK, Rakwal R, Yonekura M, Kubo A, Saji H. 2002. Proteome analysis of differentially displayed proteins as a tool for investigating ozone stress in rice (Oryza sativa L.) seedlings. Proteomics 2: 947-959.

Andrews DL, MacAlpine DM, Johnson JR, Kelley PM, Cobb BG, Drew MC. 1994. Differential induction of mRNAs for the glycolytic and ethanolic fermentative pathways by hypoxia and anoxia in maize seedlings. Plant Physiol. 106: $1575-1582$.

Blokhina O, Virolainen E, Fagerstedt KV. 2003. Antioxidants, Oxidative Damage and Oxygen Deprivation Stress: a Review. Annals of Botany 91: 179-194.

Conklin PL, Last RL. 1995. Differential accumulation of antioxidant mRNAs in Arabidopsis thaliana exposed to ozone. Plant Physiol. 109: 203-212.

Creissen G, Firmin J, Fryer M, Kular B, Leyland N, Reynolds H, Pastori G, Wellburn F, Baker N, Wellburn A, Mullineaux P. 1999. Elevated glutathione biosynthetic capacity in the chloroplasts of transgenic tobacco plants paradoxically causes increased oxidative stress. Plant Cell 11: 1277-1292.

Ewing B, Green P. 1998. Base-Calling of Automated Sequencer Traces Using Phred. II. Error Probabilities. Genome Res. 8: 186-194.

Fiscus EL, Reid CD, Miller JE, Heagle AS. 1997. Elevated $\mathrm{CO}_{2}$ reduces $\mathrm{O}_{3}$ flux and $\mathrm{O} 3$-induced yield losses in soybeans: possible implications for elevated $\mathrm{CO} 2$ studies. J. Exp. Bot. 48: 307-313.

Glick RE, Schlagnhaufer CD, Arteca RN, Pell EJ. 1995. Ozone-Induced Ethylene Emission Accelerates the Loss of Ribulose-1,5-Bisphosphate Carboxylase/Oxygenase and Nuclear-Encoded mRNAs in Senescing Potato Leaves. Plant Physiol. 109: 891-898.

Greenberg JT, Guo A, Klessig DF, Ausubel FM. 1994. Programmed cell death in plants: A pathogen-triggered response activated coordinately with multiple defense functions. Cell 77: 551-563.

Huang X, Madan A. 1999. CAP3: A DNA Sequence Assembly Program. Genome Res. 9: 868-877.

Hwang IT, Kim YJ, Kim SH, Kwak CI, Gu YY, Chun, JY. 2003. Annealing control primer system for improving specificity of PCR amplification. BioTechniques 35: 1180-1184.

Hwang KC, Cui XS, Park SP, Shin MR, Park SY, Kim EY, Kim NH. 2004. Identification of differentially regulated genes in bovine blastocysts using an annealing control 
primer system. Mol. Reprod. Dev. 69: 43-51.

Kagaya Y, Nakamura H, Ejiri SI, Tsutsumi KI, Hidaka S. 1995. The promoter from the rice nuclear gene encoding chloroplast aldolase confers mesophyll-specific and light-regulated expression in transgenic tobacco. Mol. Genet. and Genomics 248: 668-674.

Kawasaki S, Borchert C, Deyholos M, Wang H, Brazille S, Kawai K, Galbraith D, Bohnert HJ. 2001. Gene Expression Profiles during the Initial Phase of Salt Stress in Rice. The Plant Cell 13: 889-905.

Kliebenstein DJ, Monde RA, Last RL. 1998. Superoxide dismutase in Arabidopsis: an eclectic enzyme family with disparate regulation and protein localization. Plant Physiol. 118: 637-650.

Kubo A, Saji H, Tanaka K, Kondo N. 1995. Expression of Arabidopsis cytosolic ascorbate peroxidase gene in response to ozone or sulfur dioxide. Plant Mol. Biol. 29: 479-489.

Lee JE, Koo BC, Kim YG, Park HK, Kwon YU, Lee BM. 2006. Responses of physiological to ozone stress in soybean. Korean J. Crop Sci. 51: 310-311.

Lee S, Yun S. 2006. The ozone stress transcriptiome of pepper (Capsicum annuum L.). Mol. Cells 21: 197-205.

Li S, Chou HH. 2004. LUCY2: an interactive DNA sequence quality trimming and vector removal tool. Bioinformatics 20: 2865-2866.

Ludwikow A, Gallois P, Sadowski J. 2004. Ozone-induced oxidative stress response in Arabidopsis: transcription profiling by microarray approach. Cell. Mol. Biol. Lett. 9: 829-842.

Maccarrone M, Veldink GA, Vliegenthart JFG. 1992. Thermal injury and ozone stress affect soybean lipoxygenases expression. FEBS Lett. 309: 225-230.

McClung CR. 1997. Regulation of Catalases in Arabidopsis. Free Radic. Biol. Med. 23: 489-496.

Miller JD, Arteca RN, Pell EJ. 1999. Senescence-Associated Gene Expression during Ozone-Induced Leaf Senescence in Arabidopsis. Plant Physiol. 120: 1015-1024.

Mittler R. 2002. Oxidative stress, antioxidants and stress tolerance. Trends Plant Sci. 7: 405-410.

Morgan PB, Ainsworth EA, Long SP. 2003. How does elevated ozone impact soybean? A meta-analysis of photosynthesis, growth and yield. Plant, Cell \& Environment 26: 1317-1328.

Overmyer K, Brosché M, Kangasjärvi J. 2003. Reactive oxygen species and hormonal control of cell death. Trends Plant Sci. 8: 335-342.

Pasqualini S, Piccioni C, Reale L, Ederli L, Della Torre G,
Ferranti F. 2003. Ozone-Induced Cell Death in Tobacco Cultivar Bel W3 Plants. The Role of Programmed Cell Death in Lesion Formation. Plant Physiol. 133: 1122-1134.

Rao M, Koch J, Davis K. 2000. Ozone: a tool for probing programmed cell death in plants. Plant Mol. Biol. 44: 345 $-358$.

Rao MV, Lee HI, Davis KR. 2002. Ozone-induced ethylene production is dependent on salicylic acid, and both salicylic acid and ethylene act in concert to regulate ozone-induced cell death. The Plant J. 32: 447-456.

Renaud JP, Allard G, Mauffette Y. 1997. Effects of ozone on yield, growth, and root starch concentrations of two alfalfa (Medicago sativ A L.) cultivars. Environ. Pollut. 95: 273-281.

Seki M, Narusaka M, Ishida J, Nanjo T, Fujita M, Oono Y, Kamiya A, Nakajima M, Enju A, Sakurai T, Satou M, Akiyama K, Taji T, Yamaguchi-Shinozak K, Carninci P, Kawai J, Hayashizaki Y, Shinozaki K. 2002. Monitoring the expression profiles of 7000 Arabidopsis genes under drought, cold and high-salinity stresses using a full-length cDNA microarray. The Plant J. 31: 279-292.

Sharma YK, Davis KR. 1997. The Effects of Ozone on Antioxidant Responses in Plants. Free Radic. Biol. Med. 23: 480-488.

Tamaoki M, Nakajima N, Kubo A, Aono M, Matsuyama T, Saji H. 2003a. Transcriptome analysis of $\mathrm{O}_{3}$-exposed Arabidopsis reveals that multiple signal pathways act mutually antagonistically to induce gene expression. Plant Mol. Biol. 53: 443-456.

Tamaoki M, Matsuyama T, Kanna M, Nakajima N, Kubo A, Aono M, Saji H. 2003b. Differential ozone sensitivity among Arabidopsis accessions and its relevance to ethylene synthesis. Planta 216: 552-560.

Tenhaken R, Levine A, Brisson LF, Dixon RA, Lamb C. 1995. Function of the oxidative burst in hypersensitive disease resistance. Proc. Natl. Acad. Sci. U.S.A. 92: 4158 $-4163$.

Tognolli M, Penel C, Greppin H, Simon P. 2002. Analysis and expression of the class III peroxidase large gene family in Arabidopsis thaliana. Gene 288: 129-138.

Umeda M, Uchimiya H. 1994. Differential Transcript Levels of Genes Associated with Glycolysis and Alcohol Fermentation in Rice Plants (Oryza sativa L.) under Submergence Stress. Plant Physiol. 106: 1015-1022.

Yamada S, Komori T, Hashimoto A, Kuwata S, Imaseki H, Kubo T. 2000. Differential expression of plastidic aldolase genes in Nicotiana plants under salt stress. Plant Sci. 154: 61-69. 